Check for updates

Cite this: RSC Adv., 2017, 7, 32357

Received 18th April 2017

Accepted 12th June 2017

DOI: $10.1039 / \mathrm{c} 7 \mathrm{ra0} 4331 \mathrm{~g}$

rsc.li/rsc-advances

\section{Fabrication of a new biosensor based on a Sn doped ceria nanoparticle modified glassy carbon paste electrode for the selective determination of the anticancer drug dacarbazine in pharmaceuticals $\dagger$}

\begin{abstract}
Mohamed Ibrahim, (D) * Yassien Temerk and Hossieny Ibrahim
A new tin doped ceria nanoparticle modified glassy carbon paste electrode $\left(\mathrm{Sn}-\mathrm{CeO}_{2} \mathrm{NPs} / \mathrm{GCPE}\right)$ was fabricated for the determination of the anticancer drug dacarbazine (DTIC). The $\mathrm{Sn}-\mathrm{CeO}_{2}$ nanoparticles with $\mathrm{Sn}$ concentrations from 0 to $10 \mathrm{wt} \%$ were synthesized by sol gel method. Sn doped $\mathrm{CeO}_{2}$ nanoparticles were characterized by X-ray diffraction, energy-dispersed X-ray spectrometry (EDS) and transmission electron microscopy (TEM). Cyclic voltammetry (CV) and square wave voltammetry (SWV) were applied to investigate the unique properties of the $\mathrm{Sn}-\mathrm{CeO}_{2} \mathrm{NPs} / \mathrm{GCPE}$. The modified electrode showed an excellent character for electrocatalytic oxidization of DTIC, while the bare GCPE electrode only gave a small oxidation peak. The fabricated sensor showed an excellent anti-interference ability against electroactive species and metal ions. This modified electrode was used as a sensor for determination of DTIC in human biological fluids and in pharmaceutical samples with satisfactory results.
\end{abstract}

\section{Introduction}

The detection and quantification of electrochemically active compounds such as the anticancer drug dacarbazine in biological fluids like blood and urine are important to diagnose and monitor several diseases, besides supplying information about the interactions involving these species in the physiological processes. Dacarbazine [5-(3,3-dimethyl-l-triazenyl)imidazole-4-carboxamide] (DTIC) (Scheme 1) is an important antitumor agent with a proven activity and selectivity against various types of malignant diseases,

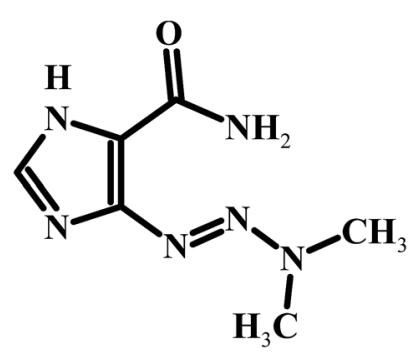

Scheme 1 Structure of DTIC.

Chemistry Department, Faculty of Science, Assiut University, Assiut 71516, Egypt. E-mail: msayed217@yahoo.co.uk; msayed217@aun.edu.eg; Hossienyomer@yahoo. com; hossieny.ibrahim@aun.edu.eg; Temerk44@yahoo.com; temerk@aun.edu.eg; Fax: +2088 2080209; Tel: +20882080508

$\uparrow$ Electronic supplementary information (ESI) available. See DOI: 10.1039/c7ra04331g such as soft tissue sarcoma and lung carcinoma. It has also been used in combination with other medications for treating Hodgkin's lymphoma., ${ }^{1,2}$ Dacarbazine is a member of the class of alkylating agents, which destroy cancer cells by adding an alkyl group to their DNA. The widespread use of dacarbazine and the need for clinical and pharmaceutical studies require fast and sensitive analytical techniques to determine this drug in a variety of biological fluids and in quality control.,

Several time consuming and expensive techniques for detection of DTIC have been studied and reported, which include chromatography ${ }^{5-7}$ and spectrometry. ${ }^{8}$ One of the broadly exercised simple, swift, and exact methods is electrochemical method. There are few reported electrochemical methods, have been applied for the determination of DTIC.9-11 Among all the above, electrochemical methods have shown remarkable advantages in the analysis of drugs in pharmaceutical preparations and human body fluids. These advantages are mainly due to the simplicity, low cost and relatively short analysis times of these compounds as compared to the other routine analytical techniques including chromatography. ${ }^{12,13}$ Further handling this technique requires a knowledge regarding the working electrode, where the electrode reactions are centered. Relatively a newly adopted method for the improvement of analyte and surface interaction is the modification of the electrode surface. For the modification of electrode surface, varieties of methods are used which include, nanoparticle incorporation on the surface of the electrode. Unique characters and vast potential application in nanodevice fabrication nanomaterials have engrossed, broad notice. ${ }^{14-16}$ 
Nanostructured metal oxides such as $\mathrm{ZnO}, \mathrm{Fe}_{3} \mathrm{O}_{4}, \mathrm{SnO}_{2}$, $\mathrm{CeO}_{2}, \mathrm{In}_{2} \mathrm{O}_{3}$ and others have recently aroused much interest as immobilizing matrices for chemo-biosensor development due to their interesting nanomorphological, functional, biocompatible and catalytic properties. ${ }^{17-20}$ Further chemical doping with appropriate elements (Fe, $\mathrm{Cr}, \mathrm{Co}, \mathrm{Mn}, \mathrm{Ni}$, etc.) is widely used as an effective method to tune surface states, energy levels of semiconductors and transport performance of carriers, and enhance the electrical, electrochemical and magnetic properties of materials. ${ }^{21-27}$ Among these, the design of $\mathrm{CeO}_{2}$ nanomaterials with controlled morphologies is of special interest due to their favorable shape-dependent properties. ${ }^{28-30}$ Different strategies are adopted to improve the physico-chemical properties and morphology of the nanostructured $\mathrm{CeO}_{2}$ in order to achieve high sensitivity and selectivity. Recently, metal-doped ceria nanomaterials have been widely considered to promote the active oxygen content on ceric oxide nanoparticles $\left(\mathrm{CeO}_{2}-\right.$ NPs) surface by changing the surface element composition, because such materials ultimately reveal strikingly high catalytic activity. ${ }^{31}$ Chemical doping into $\mathrm{CeO}_{2}$ matrix with appropriate dopants (B or In) at $\mathrm{Ce}^{4+}$ site is proved to be highly effective for chemo-biosensing applications. ${ }^{32,33}$ The added active elements stabilize the $\mathrm{CeO}_{2}$ surface, and promote a decrease in grain size which enhances higher catalytic activity and sensor response than that of pure $\mathrm{CeO}_{2}$. Hence in this work, a novel $\mathrm{Sn}-\mathrm{CeO}_{2} \mathrm{NPs}$ modified glassy carbon microspheres paste electrode ( $\mathrm{Sn}-\mathrm{CeO}_{2} \mathrm{NPs} / \mathrm{GCPE}$ ) was prepared and applied for selective and sensitive electrochemical determination of DTIC without physiological interferents.

\section{Experimental}

\subsection{Chemicals}

DTIC, cerium(III) nitrate hydrate, ten chloride pentahydrate and polyvinylalcohol polymer (PVA) (MW $=30000 \mathrm{~g} \mathrm{~mol}^{-1}$ ), were purchased from Sigma-Aldrich chemicals (St.Louis, Mo, USA). Glassy carbon spherical microparticles with a diameter of 0.4$12 \mu \mathrm{m}$ and mineral oil were obtained from Alfa Aesar (Ward Hill, MA). A stock solution of DTIC $\left(1 \times 10^{-3} \mathrm{M}\right)$ was prepared by dissolving an appropriate amount of the drug in ultrapure water and storing the solution in the dark at $4{ }^{\circ} \mathrm{C}$. Electrochemical cells and volumetric flasks were protected from light by means of aluminium foil to avoid DTIC photodecomposition. Phosphate buffer solution (PBS) was prepared from $\mathrm{NaH}_{2} \mathrm{PO}_{4}$ and $\mathrm{Na}_{2} \mathrm{HPO}_{4}(0.2 \mathrm{M})$ and adjusted the $\mathrm{pH}$ with $0.1 \mathrm{M}$ $\mathrm{H}_{3} \mathrm{PO}_{4}$ or $\mathrm{NaOH}$ solution. The $\mathrm{pH}$ values of the buffer solutions were measured with a digital radiometer $\mathrm{pH}$ meter, Jenway 3310 accurate to \pm 0.02 unit. Ultrapure water (Milli-pore Inc., 18.2 M $\Omega$ $\mathrm{cm}$ ) was obtained from a Milli-Q purification system and used in all experiments.

\subsection{Instrumentation}

Cyclic voltammetry (CV) and square-wave voltammetry (SWV) were performed using an EG\&G PAR 384 B (Princeton Applied Research, Oak Ridge, TN, USA) polarographic analyzer controlled by 394 software in conjunction with a PAR Model
303A. The electrode system consisted of the glassy carbon paste electrode (unmodified or modified) as the working electrode, a $\mathrm{Ag} / \mathrm{AgCl}$ (saturated $\mathrm{KCl}$ ) reference electrode and a $\mathrm{Pt}$ wire auxiliary electrode. A PAR Model 305 stirrer was used for SWV. For anodic stripping experiments an accumulation potential $\left(E_{\text {acc }}\right)$ was applied for a certain accumulation time $\left(t_{\mathrm{a}}\right)$, while the solution was stirred at $400 \mathrm{rpm}$. At the end of the accumulation period the stirrer was stopped and the solution was allowed to become quiescent for $15 \mathrm{~s}$ prior of the voltammetric scan. The surface morphology of the samples is analyzed by transmission electron microscopy, TEM (FEI, TECNAI, G2 spirit twin) using an accelerating voltage of $120 \mathrm{kV}$. Specimens for TEM are prepared by ultrasonic dispersion of some powder sample in ethanol and putting a droplet of the suspension on a copper microscope grid covered with carbon.

\subsection{Preparation of $\mathrm{Sn}-\mathrm{CeO}_{2} \mathrm{NPs}$ and $\mathrm{CeO}_{2} \mathrm{NPs}$}

In the present study, Sn doped $\mathrm{CeO}_{2}$ NPs was synthesized by the sol-gel combustion hybrid method using PVA as a fuel. First, the PVA bulk solution was prepared by dissolving $20 \mathrm{~g}$ of PVA powder in $500 \mathrm{~mL}$ distilled water at $90{ }^{\circ} \mathrm{C}$ and continuous stirring for $3 \mathrm{~h}$ before left to cool at room temperature. Subsequently, $5 \mathrm{~g}$ cerium(III) nitrate hydrate and tin chloride ( 5 and $10 \mathrm{wt}$ per \%) were added into $100 \mathrm{~mL}$ PVA solution and stirred continuously for $6 \mathrm{~h}$. The obtained sol was slowly heated to evaporate the solvent and it forms a hard homogeneous gel. The pyrrolysis of the final gel was performed at a temperature of $800{ }^{\circ} \mathrm{C}$ for 4 hours. During the pyrrolysis process the PVA polymeric network through the outer surface, cerium nitrate salt and tin chloride simultaneously calcinated and converted into $\mathrm{Sn}$ doped $\mathrm{CeO}_{2} \mathrm{NPs}$ ( $\mathrm{Sn}-\mathrm{CeO}_{2} \mathrm{NPs}$ ). The obtained sample was crushed to prepare a fine powder. The $\mathrm{CeO}_{2} \mathrm{NPs}$ were prepared using the same procedure without adding tin chloride into the synthesis process. Characterizations of the obtained nanoparticles are done by XRD, EDS and TEM. XRD patterns of the undoped $\mathrm{CeO}_{2} \mathrm{NPs}$ and $\mathrm{Sn}$ doped $\mathrm{CeO}_{2} \mathrm{NPs}$ were recorded using a Bruker AXS D8 advanced diffractometer with $\mathrm{Cu} \mathrm{K} \alpha$ radiation $(\lambda=1.5406 \AA)$ in the range of $20-80^{\circ}$. The average crystallite sizes were calculated using Debye Scherrer formula:

$$
D=K \lambda / \beta \cos \theta
$$

where $K$ is the shape factor whose value is taken as $0.89, \lambda$ is the wavelength of $\mathrm{Cu}, \mathrm{K} \alpha$ radiation, and $\beta$ is the corrected full width at half maximum (FWHM) of the diffraction peak and $\theta$ is the diffracting angle.

\subsection{Electrode preparation and modification}

The unmodified glassy carbon paste electrode (GCPE) was prepared with the composition of $75: 25$ (glassy carbon powder : paraffin oil) using a mortar and pestle and allowed to undergo self-homogenization. The paste was packed firmly into the cavity of a Teflon tube ( $3 \mathrm{~mm}$ diameter) to a depth of $6 \mathrm{~mm}$, and an electrical contact was achieved via a copper wire. The surface of the resulting paste electrode was smoothed and rinsed carefully with double distilled water. The undoped 
$\mathrm{CeO}_{2} \mathrm{NPs} / \mathrm{GCPE}$ was prepared by mixing the optimal amount of glassy carbon powder, paraffin oil and $\mathrm{CeO}_{2} \mathrm{NPs}$ (75:15:10 w/ w). The modified $\mathrm{Sn}-\mathrm{CeO}_{2} \mathrm{NPs} / \mathrm{GCPE}$ was fabricated by mixing of $(75: 15: 10 \mathrm{w} / \mathrm{w})$ ratio of glassy carbon/paraffin oil/Sn$\mathrm{CeO}_{2} \mathrm{NPs}$. Whenever necessary a new surface was obtained by pushing out an excess of paste and polish it on paper. Therefore the main advantages of the newly fabricated electrode are that the technique for its preparation is simple and require only short periods of time. In addition, the prepared modified electrode is renewable and low in cost compared to the literature methods. Nevertheless the materials for fabrication of the modified electrode are cheap and commercially available.

\subsection{Preparation and analysis of real samples}

Human serum and urine samples were obtained from healthy volunteers at the Hospital of Assiut University and stored in refrigerator immediately after collection before used. Ten milliliters of the urine sample was centrifuged for $30 \mathrm{~min}$ at $3000 \mathrm{rpm}$. The supernatant was filtered out using $0.45 \mu \mathrm{m}$ Millipore filter and then diluted 50 times with PBS of $\mathrm{pH}$ 4. The solution was transferred into the voltammetric cell to be analyzed without any further pretreatment. One milliliter of the serum sample was treated with $5 \mathrm{~mL}$ of methanol and centrifuged at $4000 \mathrm{rpm}$ for $20 \mathrm{~min}$ to remove the precipitating materials. Afterwards the separated serum was attenuated 10fold with $\mathrm{pH} 4.0$ phosphate buffer solutions. Then, $2.0 \mathrm{~mL}$ of this test solution was transferred into the electrochemical cell to determine DTIC by SWV method.

Dacarbazine vial labelled to contain $200 \mathrm{mg}$ DTIC per vial was used as samples. The composition of the investigated DTIC vial was dacarbazine (42\%), mannitol (16\%) and citric acid monohydrate $(42 \%)$. A weight portion of the powder content equivalent to $1 \times 10^{-3} \mathrm{M}$ of DTIC was transferred into a $25 \mathrm{~mL}$ calibrated flask and filled to the volume with ultrapure water and stored in dark at $4{ }^{\circ} \mathrm{C}$. SWV measurements were performed using the standard addition method.

\section{Results and discussion}

\subsection{XRD, EDS and TEM analysis of $\mathrm{CeO}_{2} \mathrm{NPs}$ and Sn-doped $\mathrm{CeO}_{2} \mathrm{NPs}$}

The structural properties of the undoped $\mathrm{CeO}_{2}$ and $\mathrm{Sn}(5 \mathrm{wt} \%)$ doped $\mathrm{CeO}_{2}$ nanoparticles were investigated by powder XRD method (Fig. 1A). It is clear that the diffraction peaks of all the samples correspond to the (111), (200), (220) and (311) planes that can be indexed to the cubic fluorite structure of $\mathrm{CeO}_{2}$ crystals. No characteristic peaks related to $\mathrm{Sn}$ and impurity peaks appear in XRD patterns in comparison with the standard XRD patterns of bulk $\mathrm{CeO}_{2}$ (JCPDS card No. 04-016-6759) which show that all $\mathrm{Sn}$ atoms have entered into $\mathrm{CeO}_{2}$ lattice. However, upon increasing the tin content, a moderate decrease in the intensity of diffraction peaks, accompanied by a pronounced broadening, has been observed. This can be attributed to the decrease of particle size, doping of $\mathrm{CeO}_{2}$ with $\mathrm{Sn}$ through the formation of a Sn-Ce solid solution and/or to induced microstrain..$^{34}$ This is consistent with the fact that the ionic radius of $\mathrm{Sn}^{4+}(0.74 \AA)$ is smaller than that of $\mathrm{Ce}^{4+}(0.97 \AA)$. The XRD results showed that the $\mathrm{Sn}^{4+}$ ions incorporate into $\mathrm{CeO}_{2}$ lattice or replace $\mathrm{Ce}^{4+}$ sites without changing the cubic fluorite structure. The average crystallite sizes evaluated by the Scherrer equation were found to be 30 and $16.56 \mathrm{~nm}$ for undoped $\mathrm{CeO}_{2}$
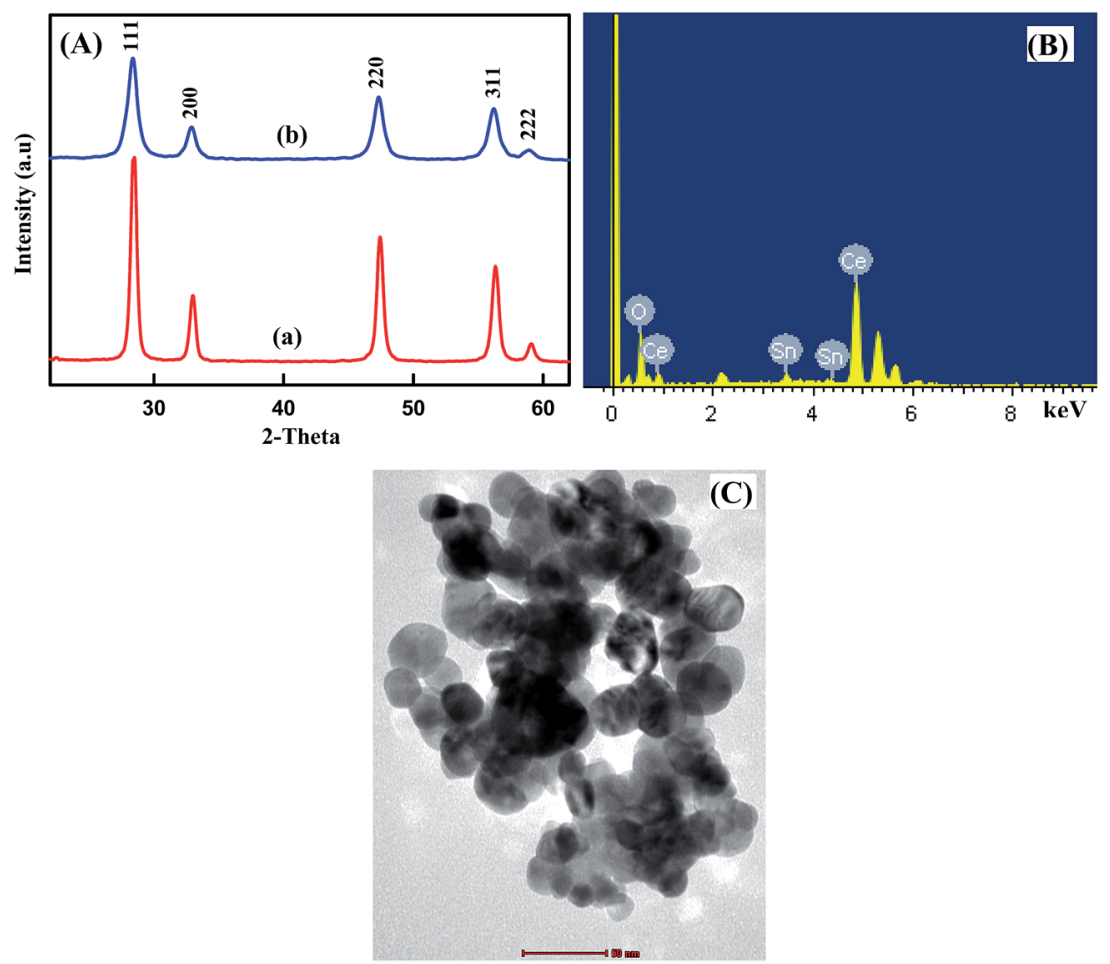

Fig. 1 (A) XRD patterns of (a) undoped $\mathrm{CeO}_{2} \mathrm{NPs}$ and (b) 5 wt\% $\mathrm{Sn}$ doped $\mathrm{CeO}_{2} \mathrm{NPs}$, EDX spectra (B), TEM image (C) of $5 \% \mathrm{Sn}$ doped CeO $\mathrm{NPs}$ 
and $5 \mathrm{wt} \% \mathrm{Sn}$ doped $\mathrm{CeO}_{2}$ nanoparticles, respectively, suggesting that the grain growth is suppressed due to doping of Sn into Ce-site.

To assess the elemental composition of $\mathrm{Sn}-\mathrm{CeO}_{2}$, the EDS analysis was done and the result is shown in Fig. 1B. In EDS spectrum, numerous well-defined peaks were evident related to $\mathrm{Sn}, \mathrm{O}$ and Ce which clearly support that the existence of Sn ions in doped sample and confirmed the successful doping of Sn in $\mathrm{CeO}_{2}$. The obtained results are in good agreement with XRD.

The TEM image of $5 \% \mathrm{Sn}$ doped $\mathrm{CeO}_{2}$ was shown in Fig. $1 \mathrm{C}$. The morphology of the $\mathrm{Sn}$ doped $\mathrm{CeO}_{2}$ nanoparticles was uniform with well-distributed elliptical/spherical particles with average particle size of about $17.23 \mathrm{~nm}$, which is consistent with the results obtained from XRD. Most of the nanoparticles were well separated, although some of them partially aggregated. Therefore, the particle size of the samples obtained from TEM pattern was quite similar to those calculated from Scherrer's equation.

\subsection{Morphological characterization of $5 \% \mathrm{Sn}-\mathrm{CeO}_{2} \mathrm{NPs} /$ GCPE}

Fig. 2 compares the morphological features of GCPE and 5\% $\mathrm{Sn}-\mathrm{CeO}_{2} \mathrm{NPs} / \mathrm{GCPE}$ using SEM. Significant differences in the surface structure of two electrodes were observed. The SEM profile of GCPE (Fig. 2A) was characterized by a surface of nonporous spherically shaped glassy carbon powder. Despite the presence of the mineral oil, the glassy carbon microspheres were packed in close proximity, and no defined binder regions
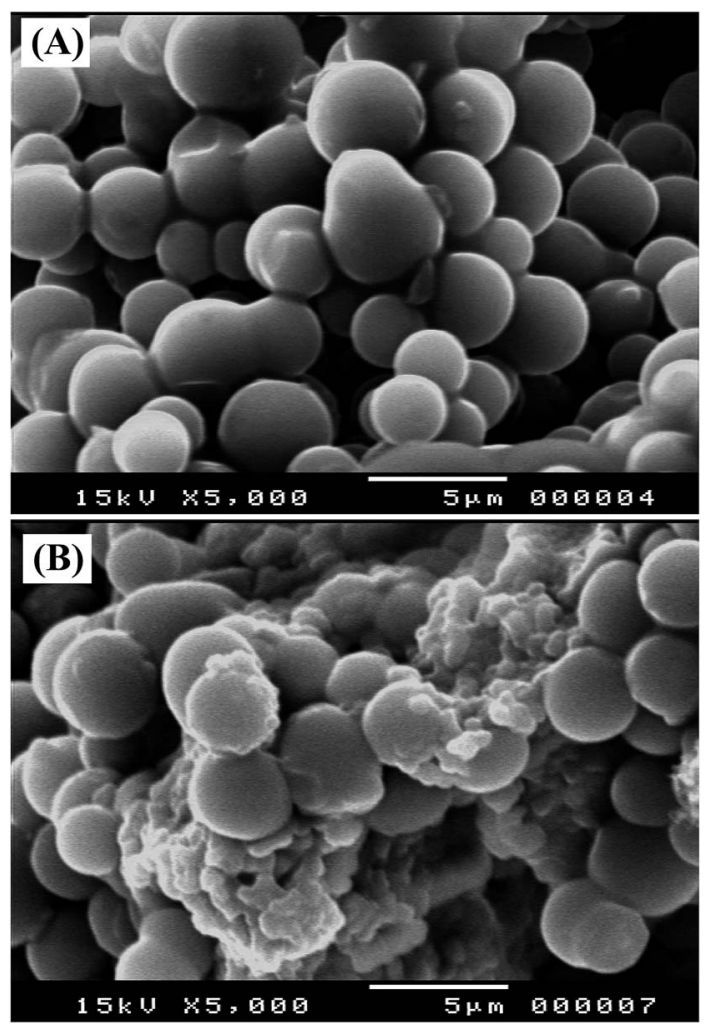

Fig. 2 SEM images of (A) GCPE and (B) $5 \%$ Sn doped $\mathrm{CeO}_{2} \mathrm{NPs} / \mathrm{GCPE}$. were visible. Apparently, the oil fills the voids between the GC spheres, while holding them together. The glassy carbon microspheres clearly decorated with $\mathrm{Sn}-\mathrm{CeO}_{2} \mathrm{NPs}$. Besides the close packing arrangement of glassy carbon microspheres, a mass of $\mathrm{Sn}-\mathrm{CeO}_{2} \mathrm{NPs}$ was filled in the gaps among the microspheres (Fig. 2B).

\subsection{Electrochemical activities of modified electrodes}

Electrochemical properties of modified electrodes were investigated using $\left[\mathrm{Fe}(\mathrm{CN})_{6}\right]^{3-/ 4-}$ as redox probes by cyclic voltammetry (Fig. 3). The cyclic voltammograms (CVs) were recorded in the presence of $5 \mathrm{mM}\left[\mathrm{Fe}(\mathrm{CN})_{6}\right]^{3-/ 4-}$ in $0.1 \mathrm{M} \mathrm{KCl}$ at the scan rate $100 \mathrm{mV} \mathrm{s}^{-1}$ for (curve 1) bare GCPE, (curve 2) $\mathrm{CeO}_{2} \mathrm{NPs}$ / GCPE and (curves 3 and 4) $\mathrm{Sn}-\mathrm{CeO}_{2} \mathrm{NPs} / \mathrm{GCPE}$ modified electrodes. At bare GCPE (curve 1), a pair of redox peaks were observed with a high capacitive background current, large peak to peak potential separation $\left(\Delta E_{\mathrm{P}}=347 \mathrm{mV}\right)$, and broadened wave shape. The $\Delta E_{\mathrm{P}}$ values for the undoped $\mathrm{CeO}_{2} \mathrm{NPs}$ (curve 2), 5 wt\% (curve 3) and 10 wt\% (curve 4) Sn doped $\mathrm{CeO}_{2} \mathrm{NPs}$ modified electrodes were found to be 206, 116 and $116 \mathrm{mV}$, respectively (Table 1 ). The undoped $\mathrm{CeO}_{2} \mathrm{NPs}$ modified GCPEs showed larger $\Delta E_{\mathrm{P}}$ value compared to that of the $5 \mathrm{wt} \%$ and 10 wt $\% \mathrm{Sn}$ doped $\mathrm{CeO}_{2} \mathrm{NPs}$ modified GCPEs. The large peak separation was assumed to result from the lower electrical conductivity.

Furthermore, the peak current intensity at $5 \mathrm{wt} \% \mathrm{Sn}-\mathrm{CeO}_{2}$ NPs/GCPE was enhanced and increased 2 times higher than that at bare GCPE indicating its improved electrochemical performance due to the Sn doping. The observed enhancement in the charge transport characteristic of $5 \mathrm{wt} \% \mathrm{Sn}-\mathrm{CeO}_{2} \mathrm{NPs}$ is in agreement with the proposal that the doping induced oxygen vacancy plays an important role in the charge transport behavior of $\mathrm{CeO}_{2} \mathrm{NPs}$. The obtained results indicated that the 5 wt\% Sn doping into $\mathrm{CeO}_{2}$ is the saturation point, and it is facilitating the charge transport between the modified electrode surface and redox couple. The observed decrement in $\Delta E_{\mathrm{P}}$ and

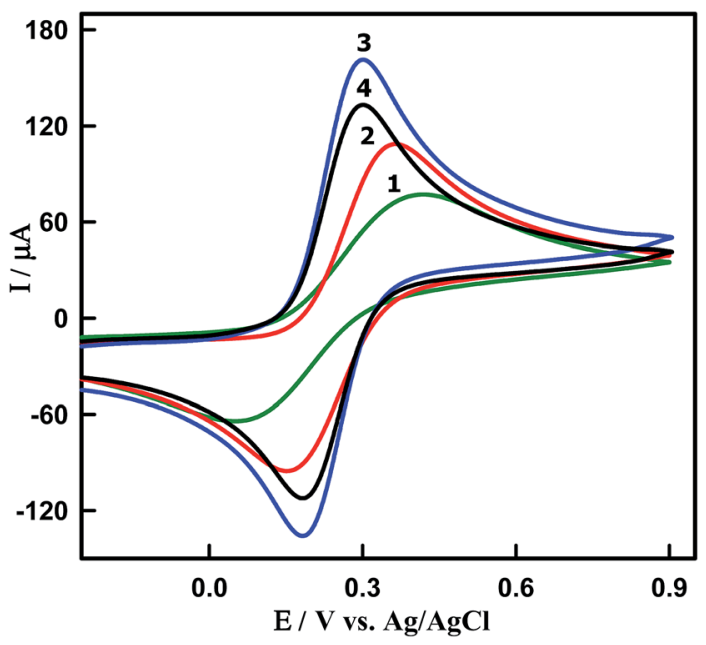

Fig. $3 \mathrm{CVs}$ of $5 \mathrm{mM}\left[\mathrm{Fe}(\mathrm{CN})_{6}\right]^{3-/ 4-}$ in $0.1 \mathrm{M} \mathrm{KCl}$ obtained at a scan rate of $0.10 \mathrm{~V} \mathrm{~s}^{-1}$. Curve 1: bare GCPE, curve 2: undoped $\mathrm{CeO}_{2} \mathrm{NPs} / \mathrm{GCPE}$, curve 3: $5 \%$ and curve 4: $10 \% \mathrm{Sn}-\mathrm{CeO}_{2} \mathrm{NPs} / \mathrm{GCPE}$. 
Table 1 Electrochemical data of $5 \mathrm{mM}\left[\mathrm{Fe}(\mathrm{CN})_{6}\right]^{3-14-}$ in $0.1 \mathrm{M} \mathrm{KCl}$ at different working electrodes

\begin{tabular}{llll}
\hline Electrodes & $\Delta E_{\mathrm{P}}(\mathrm{mV})$ & $I_{\mathrm{pa}}(\mu \mathrm{A})$ & $A^{a}\left(\mathrm{~cm}^{2}\right)$ \\
\hline $\mathrm{GCPE}$ & 347 & 90 & 0.058 \\
$\mathrm{CeO}_{2} \mathrm{NP} / \mathrm{GCPE}$ & 206 & 120 & 0.099 \\
$\mathrm{Sn}-\mathrm{CeO}_{2} \mathrm{NPs} / \mathrm{GCPE}(5 \mathrm{wt} \%)$ & 116 & 175 & 0.225 \\
$\mathrm{Sn}-\mathrm{CeO}_{2} \mathrm{NPs} / \mathrm{GCPE}(10 \mathrm{wt} \%)$ & 116 & 145 & 0.150 \\
${ }^{a}{ }_{A}$, active surface area $\left(\mathrm{cm}^{2}\right)$. & & &
\end{tabular}

the corresponding improvement in redox peak current values of $\mathrm{Sn}-\mathrm{CeO}_{2} \mathrm{NPs}$ could be attributed to faster electron transfer kinetics and larger electroactive surface area of $\mathrm{Sn}-\mathrm{CeO}_{2} \mathrm{NPs}$. In order to confirm this, the active surface area of each electrode could be calculated based on the Randles-Sevcik equation: ${ }^{35}$

$$
I_{\mathrm{P}}=2.69 \times 10^{5} n^{3 / 2} A D^{1 / 2} \nu C
$$

where $n$ is the value of electron transfer $(n=1), A$ is the active electrode area, $D$ is the diffusion coefficient $\left(7.6 \times 10^{-6} \mathrm{~cm} \mathrm{~s}^{-1}\right)$, $C$ is the concentration of $\left[\mathrm{Fe}(\mathrm{CN})_{6}\right]^{3-/ 4-}(5 \mathrm{mM})$ and $\nu$ is the scan rate. The $\mathrm{CV}$ profiles of the $\mathrm{Sn}-\mathrm{CeO}_{2} \mathrm{NPs} / \mathrm{GCPE}$ in $5 \mathrm{mM}$ $\left[\mathrm{Fe}(\mathrm{CN})_{6}\right]^{3-/ 4-}$ with different scan rates from $50-500 \mathrm{mV} \mathrm{s}^{-1}$ are shown in Fig. S1. $\uparrow$ The observed linear relation of the oxidation peak currents as a function of the square root of the scan rate reveals a diffusion-controlled process (insert of Fig. S1†). From the slope of $I_{\mathrm{P}}-\nu^{1 / 2}$, the values of $A$ are calculated to be $0.225 \mathrm{~cm}^{2}$ and $0.058 \mathrm{~cm}^{2}$ for ( $5 \mathrm{wt} \%$ ) $\mathrm{Sn}-\mathrm{CeO}_{2} \mathrm{NPs} / \mathrm{GCPE}$ and bare GCPE, respectively (Table 1 ). The difference in active surface area between the bare GCPE and the $\mathrm{Sn}-\mathrm{CeO}_{2} \mathrm{NPs} / \mathrm{GCPE}$ clearly indicates that the modified electrode possesses a larger reaction area. Hence we have used $5 \mathrm{wt} \%$ Sn doped $\mathrm{CeO}_{2}$ nanoparticles for further investigation and it is represented as $\mathrm{Sn}-\mathrm{CeO}_{2} \mathrm{NPs}$.

\subsection{Electrochemical oxidations of DTIC at the $\mathrm{Sn}-\mathrm{CeO}_{2} \mathrm{NPs} /$ GCPE}

Fig. 4A shows the CVs obtained for $8.50 \mu \mathrm{M}$ DTIC at bare GCPE (curve 1), undoped $\mathrm{CeO}_{2} \mathrm{NPs} / \mathrm{GCPE}$ (curve 2) and $\mathrm{Sn}-\mathrm{CeO}_{2} \mathrm{NPs} /$ GCPE (curve 3) in PBS (pH 4.0). According to cyclic voltammograms in Fig. 4A, no cathodic peak was observed on the reverse scan within the investigated potential range (0.0-1.2 V) because its oxidation is an electrochemically irreversible process. In this context DTIC underwent a two-electron irreversible oxidation process in aqueous media. ${ }^{11}$ Compared to those obtained at the bare GCPE $(2.33 \mu \mathrm{A})$, undoped $\mathrm{CeO}_{2} \mathrm{NPs} / \mathrm{GCPE}(7.01 \mu \mathrm{A})$, a fairly larger peak current was obtained at the $\mathrm{Sn}-\mathrm{CeO}_{2} \mathrm{NPs} / \mathrm{GCPE}$ $(24.12 \mu \mathrm{A})$. This result suggested that the electron transfer reaction at the $\mathrm{Sn}-\mathrm{CeO}_{2} \mathrm{NPs} / \mathrm{GCPE}$ is more facile than that at the bare GCPE and undoped $\mathrm{CeO}_{2} \mathrm{NPs} / \mathrm{GCPE}$. The electrocatalytic activity of the modified electrode could be ascribed to the presence of nano-Sn- $\mathrm{CeO}_{2}$ which enhanced the conductivity, surface area and facilitated the electron transfer between the biomolecules and the electrode surface.

Furthermore, the SWV was performed to obtain better sensitivity because enhanced analytical signals can be achieved by eliminating the non-faradic currents that occur with CV. As can be seen DTIC showed a sharp peak at $932 \mathrm{mV}$ in PBS $(\mathrm{pH}$ 4.0) at the $\mathrm{Sn}-\mathrm{CeO}_{2} \mathrm{NPs} / \mathrm{GCPE}$, which corresponds to the oxidation of DTIC (Fig. 4B). The peak current was $45 \mu \mathrm{A}$, much larger than that obtained by $\mathrm{CV}$. There is also an enhanced peak current of DTIC at the $\mathrm{Sn}-\mathrm{CeO}_{2} \mathrm{NPs} / \mathrm{GCPE}$ (Fig. 4B, curve 3 ) as compared to a bare GCPE (Fig. 4B, curve 1) and undoped $\mathrm{CeO}_{2} \mathrm{NPs} / \mathrm{GCPE}$ (Fig. 4B, curve 2). The results indicated that the nano-Sn- $\mathrm{CeO}_{2}$ incorporated GCPE had great enhancement peak current of DTIC, which was due to the excellent characteristics of nano-Sn- $\mathrm{CeO}_{2}$ such as high chemical stability, high surface area, good electrical conductivity and high optical transparence. So the electron transfer of DTIC on the $\mathrm{Sn}-\mathrm{CeO}_{2} \mathrm{NPs} / \mathrm{GCPE}$ was greatly enhanced without using electron transfer mediator. It is clear that the increase in oxidation current at the proposed modified electrode can offer a special approach for sensitive electrochemical determination of DTIC in biological fluids.

\subsection{Effect of potential scan rate}

The effect of the scan rate on the oxidation peak current and potential was studied in order to estimate the nature of the electrode process occurring at the $\mathrm{Sn}-\mathrm{CeO}_{2} \mathrm{NPs} / \mathrm{GCPE}$ surface. Fig. 5 presents the cyclic voltammograms of DTIC recorded in PBS of $\mathrm{pH} 4.0$ with scan rate varying from 50 to $500 \mathrm{mV} \mathrm{s}^{-1}$. The oxidation peak heights were found to increase linearly with scan rate from 50 to $500 \mathrm{mV} \mathrm{s}^{-1}$. The $I_{\mathrm{P}}$ is linearly increased with the square root of scan rate, $\nu^{1 / 2}$, in the range of $50-500 \mathrm{mV} \mathrm{s}^{-1}$ (inset of Fig. 5). This indicates that the oxidation process of DTIC in PB solution ( $\mathrm{pH} 4.0$ ) on the nano-Sn- $\mathrm{CeO}_{2}$ is a diffusion-controlled process. The effect of the potential scan rate on the peak current may be expressed as $\log \left(I_{\mathrm{pa}}\right) v s . \log (\nu)$, which has a slope of 1.0 for the species confined to the electrode surface, or 0.5 for the diffusion controlled system. The dependence of $\log \left(I_{\mathrm{pa}}\right)$ vs. $\log (\nu)$ can be expressed by the equation: $\log I_{\mathrm{P}}(\mu \mathrm{A})=0.65 \log \nu\left(\mathrm{mV} \mathrm{s}^{-1}\right)+0.11\left(R^{2}=0.9977\right)$ (Fig. S2 $\left.\dagger\right)$. The value of the slope confirms that the process is diffusioncontrolled.

Moreover, the peak potential shifted to more positive values on increasing the scan rate, which confirms the irreversibility of the oxidation process, and a linear relationship between $E_{\mathrm{P}}$ and $\log \nu$ in the range from 50 to $500 \mathrm{mV} \mathrm{s}^{-1}$ (Fig. S3†) which can be expressed as: $E_{\mathrm{P}}(\mathrm{V})=0.04 \log \nu\left(\mathrm{V} \mathrm{s}^{-1}\right)+0.97\left(R^{2}=0.993\right)$.

According to the Laviron theory for an adsorption controlled and totally irreversible electrode process, ${ }^{36} E_{\mathrm{P}}$ is defined by the following equation.

$$
E_{\mathrm{P}}=E^{\circ}-(2.3 R T / \alpha n F)\left[\log \left(R T k_{\mathrm{s}} / \alpha n F\right)-\log \nu\right]
$$

where $\alpha$ is the transfer coefficient, $k_{\mathrm{s}}$ is the heterogeneous electron transfer rate constant, $n$ is the number of electrons transferred, $\nu$ is the scan rate, and $E^{\circ}$ is the formal redox potential. Other symbols have their usual meanings. Thus value of $\alpha n$ can be easily calculated from the slope of $E_{\mathrm{P}} v s . \log \nu$. In this system, the slope was found to be 0.024 taking $T=298 \mathrm{~K}, R$ $=8.314 \mathrm{~J} \mathrm{~K}^{-1} \mathrm{~mol}^{-1}$, and $F=96480 \mathrm{C} \mathrm{mol}^{-1}$, the $\alpha n$ was calculated to be 1.069. The value of $\alpha$ can be calculated as: 

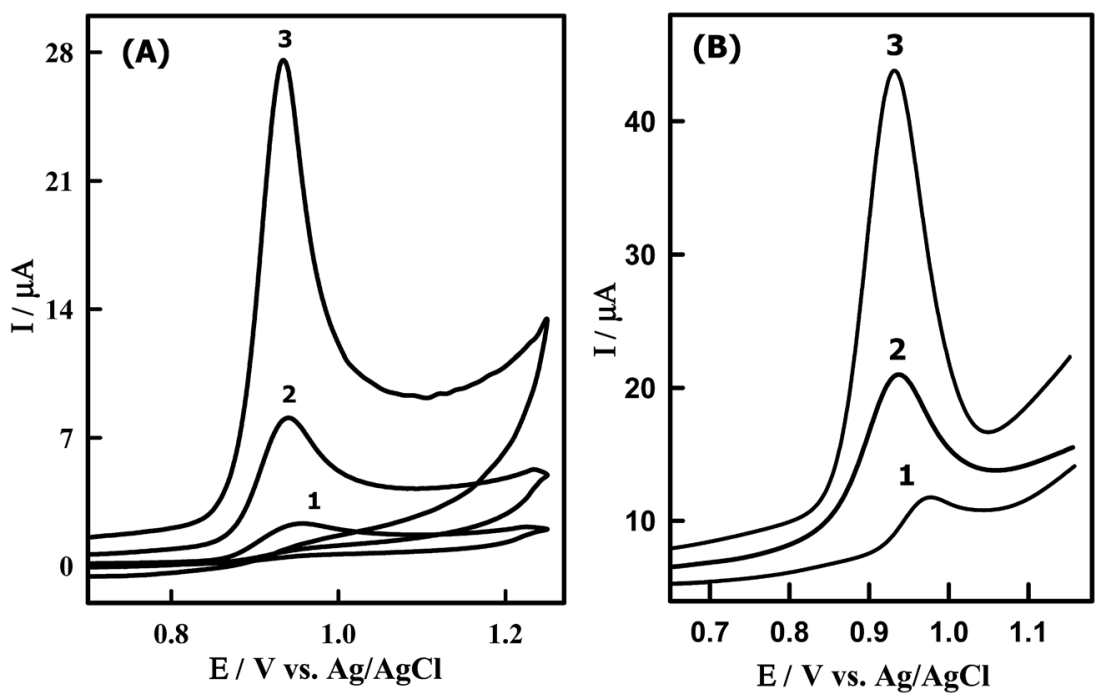

Fig. 4 (A) CVs of $8.50 \mu$ M DTIC in PBS of pH 4.0 obtained at (1) bare GCPE, (2) $\mathrm{CeO}_{2} \mathrm{NPs} / \mathrm{GCPE}$ and (3) $\mathrm{Sn}-\mathrm{CeO}_{2} \mathrm{NPs} / \mathrm{GCPE}$; scan rate, $0.10 \mathrm{~V} \mathrm{~s}{ }^{-1}$. (B) SW voltammograms of $1.14 \mu \mathrm{M}$ DTIC in PBS buffer of pH 4.0 obtained at (1) unmodified (2) modified $\mathrm{CeO}_{2} \mathrm{NPs} / \mathrm{GCPE}$ and (3) $\mathrm{Sn}-\mathrm{CeO}{ }_{2} \mathrm{NPs} /$ GCPE; accumulation potential, $0.0 \mathrm{~V}$; accumulation time, $10 \mathrm{~s}$; scan increment, $6 \mathrm{mV}$; frequency, $120 \mathrm{~Hz}$ and pulse height, $35 \mathrm{mV}$ pp.

$$
E_{\mathrm{P}}-E_{\mathrm{P} / 2}=(47.7 / \alpha) \mathrm{mV}
$$

where $E_{\mathrm{P} / 2}$ is the potential when the current is at half the peak value. From this, we obtained the value of $\alpha$ to be 0.54 for Sn$\mathrm{CeO}_{2} \mathrm{NPs} / \mathrm{GCPE}$. So, the number of electrons $(n)$ transferred in the electrooxidation of DTIC was calculated to be $1.979 \approx 2$ that value is in good agreement with the value reported in the literature. ${ }^{11}$ The value of $k_{\mathrm{s}}$ can be determined from the intercept of the previous plot if the value of $\alpha n$ and $E^{\circ}$ are known. The value of $E^{\circ}$ can be obtained from the intercept of $E_{\mathrm{P}} v s . \nu$ curve by extrapolating to the vertical axis at $\nu=0 \mathrm{~V} \mathrm{~s}^{-1}$. Thus, using this information and eqn (1) the $k_{\mathrm{s}}$ values obtained were 0.782 and $2.356 \mathrm{~s}^{-1}$ for bare and modified electrodes, respectively. These results may be attributed to the good electrical conductivity as

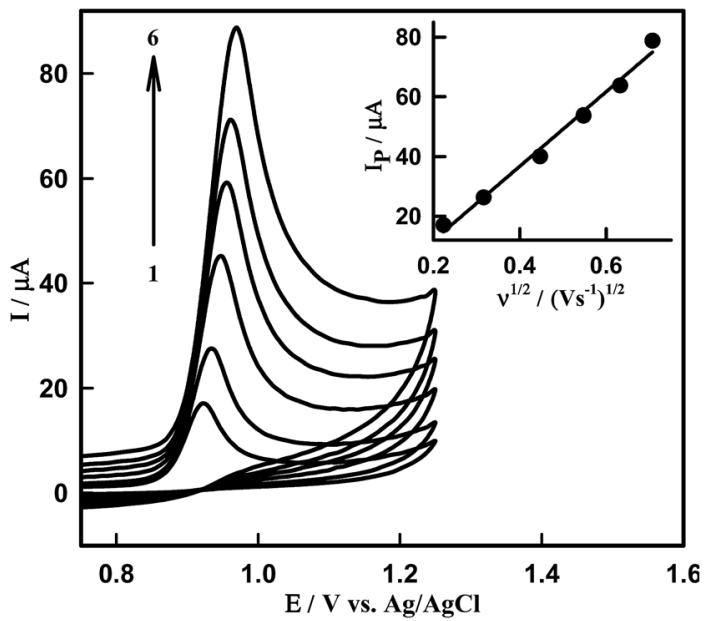

Fig. $5 \mathrm{CVs}$ of $8.50 \mu \mathrm{M}$ DTIC on surface of $\mathrm{Sn}-\mathrm{CeO}_{2} \mathrm{NPs} / \mathrm{GCPE}$ at various scan rates; (1) 50, (2) $100,(3) 200$, (4) 300, (5) 400 and (6) $500 \mathrm{mV} \mathrm{s}^{-1}$ in PBS of $\mathrm{pH} 4$.0. Inset: dependence of peak current on square root of scan rate. well as the increase of the electrode surface area in the presence of $\mathrm{Sn}$ doped $\mathrm{CeO}_{2}$ nanoparticles and suggested that electron transfer process between the DTIC molecules and $\mathrm{Sn}-\mathrm{CeO}_{2} \mathrm{NPs} /$ GCPE was very fast.

The surface concentration $\left(\Gamma, \mathrm{mol} \mathrm{cm} \mathrm{c}^{-2}\right)$ of electroactive DTIC on the modified electrode $\mathrm{Sn}-\mathrm{CeO}_{2} \mathrm{NPs} / \mathrm{GCPE}$ and bar GCPE can be calculated from the slope of the plot of $I_{\mathrm{pa}}$ versus scan rate by: ${ }^{37} I_{\mathrm{P}}=n^{2} F^{2} \nu A \Gamma / 4 R T$ where $n$ is the number of electrons transferred, $F\left(\mathrm{C} \mathrm{mol}^{-1}\right)$ is the Faraday's constant, $A$ $\left(\mathrm{cm}^{2}\right)$ is the area of the electrode, $\Gamma$ is the surface concentration of the electroactive substance, DTIC, and $\nu\left(\mathrm{V} \mathrm{s}^{-1}\right)$ is the scan rate. The surface concentration $(T)$ of DTIC on the $\mathrm{Sn}-\mathrm{CeO}_{2} \mathrm{NPs} /$ GCPE was estimated to be $6.25 \times 10^{-10} \mathrm{~mol} \mathrm{~cm}{ }^{-2}$, which was larger than $6.04 \times 10^{-11} \mathrm{~mol} \mathrm{~cm}{ }^{-2}$ on GCPE. These values imply that the presence of $\mathrm{Sn}-\mathrm{CeO}_{2}$ increases the surface area of the electrode, which in turn increases the $\Gamma$ of DTIC.

\subsection{Optimization of the amount of modifier ( $5 \% \mathrm{Sn}-$ $\mathrm{CeO}_{2} \mathrm{NPs}$ )}

The effect of the amount of $5 \% \mathrm{Sn}-\mathrm{CeO}_{2} \mathrm{NPs}$ within the glassy carbon paste electrode on the voltammetric response was evaluated by changing mass ratio of $\mathrm{Sn}-\mathrm{CeO}_{2} \mathrm{NPs}$ to glassy carbon microspheres in the glassy carbon paste (Fig. S4†). The oxidation peak current of DTIC increases with the increasing of amount of modifier because the concentration of $\mathrm{Sn}-\mathrm{CeO}_{2} \mathrm{NPs}$ on the surface of the modified electrode increases correspondingly (Fig. 6). However, when the amount of nano-Sn-CeO reaches $10 \%(\mathrm{w} / \mathrm{w})$ (nano-Sn- $\mathrm{CeO}_{2} /$ glassy carbon paste), the peak current reaches its maximum. After this point, any continuing increase in the amount of modifier causes a decrease in the peak current, due to the decrease of the conductivity of the modified electrode. Thus electrode composition of $10 \%(\mathrm{w} / \mathrm{w})$ nano-Sn- $\mathrm{CeO}_{2}, 75 \%(\mathrm{w} / \mathrm{w})$ glassy carbon microspheres and $15 \%(\mathrm{w} / \mathrm{w})$ paraffin oil was used for further experiments. 


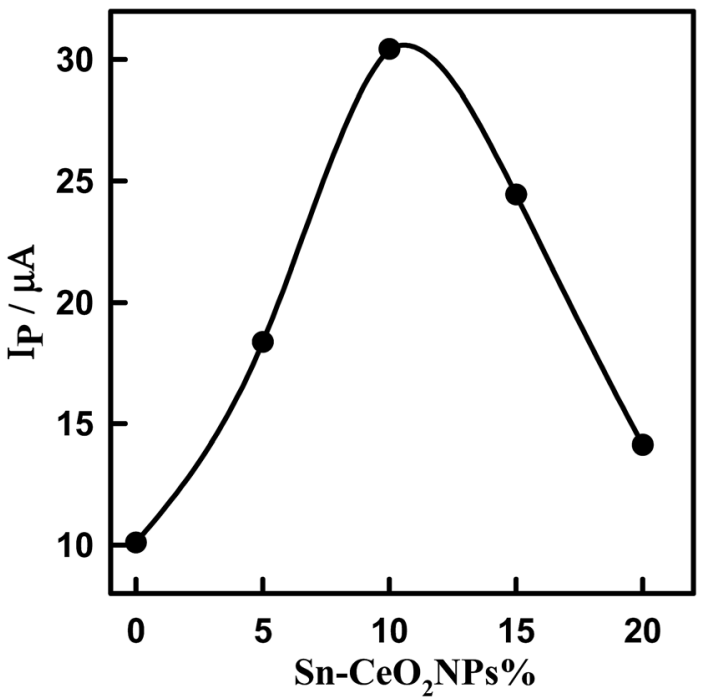

Fig. 6 Plot of peak current of $1.14 \mu$ M DTIC in PBS, pH 4.0 using SWV versus the percentage of $5 \% \mathrm{Sn}-\mathrm{CeO}_{2} \mathrm{NPs}$ in the paste.

\subsection{Optimization of $\mathbf{p H}$}

The effect of $\mathrm{pH}$ on the SWV responses of DTIC on $\mathrm{Sn}-\mathrm{CeO}_{2} / \mathrm{GCPE}$ was investigated in the $\mathrm{pH}$ range from 3 to 8.0 (Fig. 7). It can be clearly observed that the peak current and potential towards the oxidation of DTIC are closely related to the $\mathrm{pH}$ value of the supporting electrolyte. It was found that the oxidation peak potential of DTIC shifted toward less positive potential values with increase in the $\mathrm{pH}$ (Fig. S5 $\dagger$ ). This suggests the involvement of protons in the oxidation process. Based on the results obtained, over the studied $\mathrm{pH}$ range, a linear relationship was obtained between $E_{\mathrm{P}}$

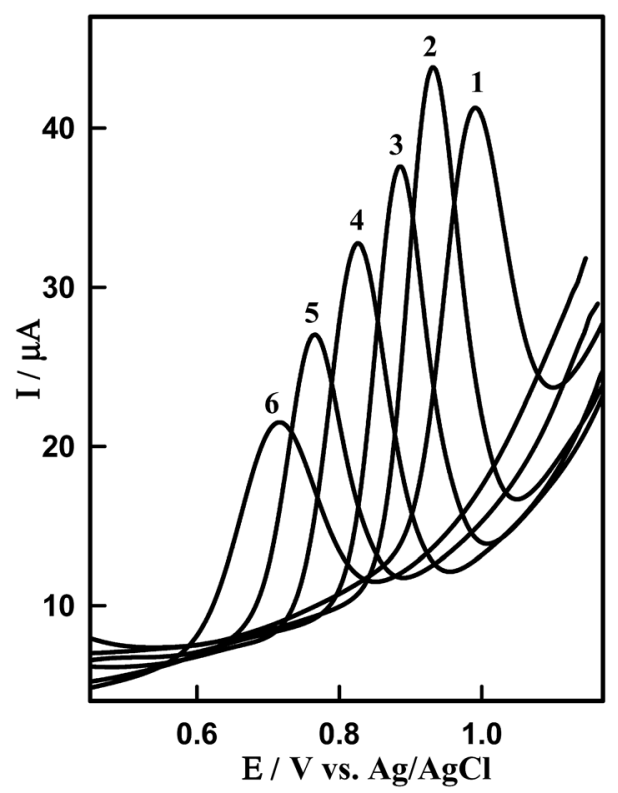

Fig. $7 \mathrm{SW}$ voltammograms of $1.14 \mu \mathrm{M}$ DTIC on the surface of Sn$\mathrm{CeO}_{2} \mathrm{NPs} / \mathrm{GCPE}$ at different $\mathrm{pH}$ values (PBS): (1) $\mathrm{pH} 3.0$, (2) $\mathrm{pH} 4.0$, (3) $\mathrm{pH}$ 5.0, (4) 6.0, (5) 7.0 and (6) 8.0. Other conditions are the same in Fig. 4B. and $\mathrm{pH}$ (Fig. S5 $\dagger$ ), which can be expressed by the following equation: $E_{\mathrm{P}}(\mathrm{V})=1015-0.057 \mathrm{pH}\left(R^{2}=0.999\right)$. A comparison between the obtained slope of $-0.057 \mathrm{~V} \mathrm{pH}^{-1}$ and the theoretical slope of $-0.059 m / n \mathrm{~V} \mathrm{pH}^{-1}$ ( $m$ and $n$ being the numbers of protons and electrons, respectively) confirms that equal numbers of protons and electrons participate in the oxidation procedure. According to the overall electrode reaction, ${ }^{\mathbf{1 1}}$ two electrons and two protons were involved in the DCIT oxidation. The height of the peak reached a maximum and the shape of the curve is better in PBS at $\mathrm{pH} 4.0\left(\mathrm{p} K_{\mathrm{a}}=4.42\right)^{38}$ than other buffers. This supporting electrolyte was chosen with respect to sharp response and better peak shape for the construction of calibration curve and for determination of DTIC in standard solution and in biological samples.

\subsection{Square-wave pulse parameters}

The optimum conditions for the SWV were recognized by measuring the current dependence on the instrumental parameters counting pulse height, frequency and scan increment. SW voltammograms of $1.14 \mu \mathrm{M}$ DTIC in PBS of $\mathrm{pH} 4.0$ onto the $\mathrm{Sn}-\mathrm{CeO}_{2} \mathrm{NPs} / \mathrm{GCPE}$ were recorded at various pulse parameters (frequency; $f=20-120 \mathrm{~Hz}$, scan increment; $\Delta E_{\mathrm{s}}=2-$ $10 \mathrm{mV}$ and pulse height; $\Delta E_{\mathrm{a}}=20-80 \mathrm{mV}$ ). The better developed voltammetric peak was obtained under the following pulse parameters: $f=120 \mathrm{~Hz}, \Delta E_{\mathrm{s}}=6 \mathrm{mV}$ and $\Delta E_{\mathrm{a}}=35 \mathrm{mV}_{\mathrm{pp}}$ using $\mathrm{Sn}-\mathrm{CeO}_{2} \mathrm{NPs} / \mathrm{GCPE}$. These parameters reflect SWVs of high sensitivity and best peak morphology.

\subsection{Square wave voltammetric determination of DTIC concentration}

Under optimum conditions, square wave voltammograms are recorded at the $\mathrm{Sn}-\mathrm{CeO}_{2} \mathrm{NPs} / \mathrm{GCPE}$ to determine the limit detection (LOD) of DTIC. Fig. 8A shows the typical SWV of different concentrations of DTIC at the modified electrode. It was found that the anodic peak current increased linearly with increasing the concentration of DTIC (Fig. 8B). A linear dynamic range of $6.40 \times 10^{-8}$ to $6.69 \times 10^{-6} \mathrm{M}$ DTIC was obtained following its concentration onto the modified electrode by adsorption accumulation for $10 \mathrm{~s}$ at $0.0 \mathrm{~V}$. The analytical results are summarized in Table 2 . In this context the sensitivity of the proposed sensor was found to be of $361.43 \mu \mathrm{A} \mu \mathrm{M}^{-1} \mathrm{~cm}^{-2}$. The LOD was calculated using the relation $k \mathrm{SDa} / b$, where $k=3$, SDa is the standard deviation of the intercept and $b$ is the slope of the calibration plot. The LOD value was found to be $3.79 \times$ $10^{-9}$ M DTIC (0.690 ng mL ${ }^{-1}$ ), which confirmed good sensitivity of the proposed sensor. This concentration detection limit of DTIC $\left(3.79 \times 10^{-9} \mathrm{M}\right)$ is very low in compared with the values reported by other reported methods. ${ }^{\mathbf{6}, 11}$ This wide linear range and low detection limit can be attributed to the effect of the Sn$\mathrm{CeO}_{2} \mathrm{NPs}$, which provides a large specific area to increase the loading amount of DTIC. Meanwhile, the electron transfer to the electrode surface can be accelerated and the electrochemical signal is amplified due to the outstanding electric conductivity of the $\mathrm{Sn}-\mathrm{CeO}_{2} \mathrm{NPs} / \mathrm{GCPE}$. Thus, the proposed method could be effectively used for the determination of DTIC in commercial samples. 


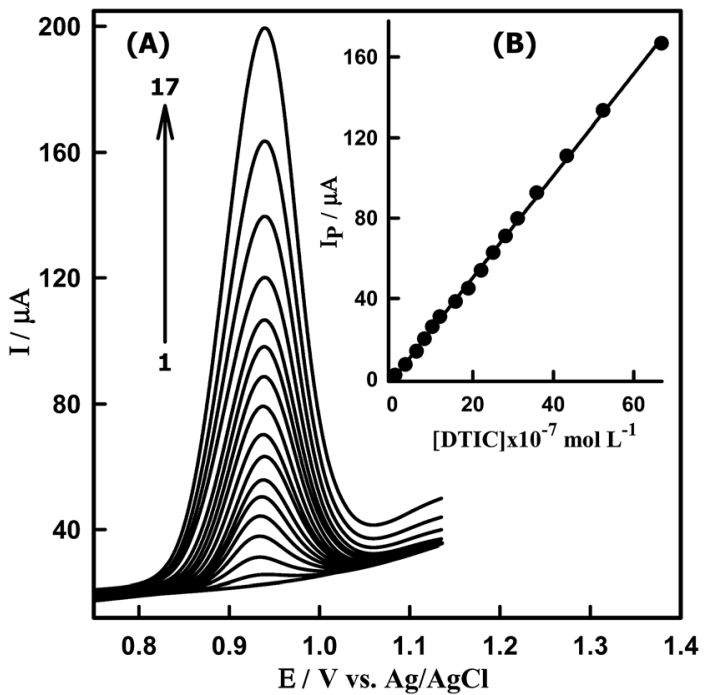

Fig. 8 (A) SW voltammograms of DTIC at $\mathrm{Sn}-\mathrm{CeO}_{2} \mathrm{NPs} / \mathrm{GCPE}$ in PBS at pH 4.0. [DTIC]: (1) blank, (2) 0.064, (3) 0.32, (4) 0.60, (5) 0.79, (6) 0.99, (7) $1.18,(8) 1.57,(9) 1.88,(10) 2.21,(11) 2.51,(12) 2.81,(13) 3.12$, (14) 3.59, (15) 4.33, (16) 5.24 and (17) $6.69 \mu \mathrm{M}$. (B) Calibration plot of $I_{P}(\mu \mathrm{A})$ versus [DTIC] in PBS of $\mathrm{pH} 4.0$.

\subsection{Interference studies}

In order to evaluate the selectivity of the proposed method for the determination of DTIC, the influence of potentially interfering substances on the determination of this compound was investigated using SWV at the $\mathrm{Sn}-\mathrm{CeO}_{2} \mathrm{NPs} / \mathrm{GCPE}$. The tolerance limit for interfering species was considered as the maximum concentration of foreign species that caused a relative error less than $\pm 5 \%$ for determination of $1.18 \mu \mathrm{M}$ DTIC under the optimized conditions. For $1.18 \mu \mathrm{M}$ of DTIC, the result showed that over 200 fold excess of ascorbic acid, uric acid, alanine, cysteine, glucose, citric acid, uracil and serine did not interfere with DTIC response (Table S1†). The results obtained show recoveries in the range from 97.88 to 102.17 for $1.18 \mu \mathrm{M}$ of DTIC solution, indicating that there were no important matrix interferences for the samples by the proposed SWV method using $\mathrm{Sn}-\mathrm{CeO}_{2} \mathrm{NPs} / \mathrm{GCPE}$. From these results, it may be
Table 3 Precision (intra and inter day) and accuracy for assay of DTIC $(n=5)$

\begin{tabular}{llllr}
\hline $\begin{array}{l}\text { Added } \\
(\mu \mathrm{M})\end{array}$ & $\begin{array}{l}\text { Found } \\
(\mu \mathrm{M})\end{array}$ & $\begin{array}{l}\text { Precision } \\
\text { RSD } \%\end{array}$ & $\begin{array}{l}\text { Relative } \\
\text { error\% }\end{array}$ & Recovery\% \\
\hline Intra-day & & & & \\
0.60 & $0.61 \pm 0.011$ & 1.80 & -1.66 & 101.66 \\
1.18 & $1.16 \pm 0.013$ & 1.12 & 1.69 & 98.31 \\
5.24 & $5.22 \pm 0.027$ & 0.52 & 0.38 & 99.62 \\
& & & & \\
Inter-day & & & & \\
0.60 & $0.58 \pm 0.016$ & 2.75 & 3.33 & 96.67 \\
1.18 & $1.20 \pm 0.022$ & 1.83 & -1.69 & 101.69 \\
5.24 & $5.17 \pm 0.096$ & 1.86 & 1.33 & 98.66 \\
\hline
\end{tabular}

concluded that the method is free from interference by most coexisting substances and shows promising properties for use in real samples.

\subsection{Stability and reproducibility of the electrode}

The $\mathrm{Sn}-\mathrm{CeO}_{2} \mathrm{NPs} / \mathrm{GCPE}$ was stable, even after 45 days if it preserved in a closed container. Daily recording the SWV of 3.2 $\times 10^{-7} \mathrm{M}$ of DTIC checked the stability of the proposed modified electrode; the electrode retained $98.55 \%$ of its initial peak current response with a standard deviation of $1.32 \%$. This shows the long-term stability of the $\mathrm{Sn}-\mathrm{CeO}_{2} \mathrm{NPs} / \mathrm{GCPE}$.

In order to evaluate the accuracy and precision of the proposed method the analysis of DTIC at three levels of low, moderate and high concentrations of the calibration curve was carried out in five independent series at the same day (intra-day) and performed at same levels on five different days (inter-day). The results obtained for intra-day and inter-day precision and accuracy are presented in Table 3. As can be seen, the RSD values of the measurements were not greater than $1.80 \%$ and $2.75 \%$ for intra-day and inter-day determinations, respectively, and the accuracy of determination was not different from added values by more than $3.33 \%$. Also the recovery of DTIC was found to be between $96.67 \%$ and $101.69 \%$. These results confirm the good precision and accuracy of the proposed method. This indicates that the $\mathrm{Sn}-\mathrm{CeO}_{2} \mathrm{NPs} / \mathrm{GCPE}$ has a good repeatability.

Table 2 Regression data of the calibration lines for quantitative determination of DTIC in standard solution, serum sample and urine sample in PBS (pH 4.0) at $\mathrm{Sn}-\mathrm{CeO}_{2} \mathrm{NPs} / \mathrm{GCPE}$ using SWV

\begin{tabular}{llll}
\hline Parameters & Standard solution & Serum sample & Urine sample \\
\hline Measured potential $(\mathrm{V})$ & 0.934 & 0.933 & 0.935 \\
Linearity range $(\mu \mathrm{M})$ & $0.064-6.69$ & $0.076-6.59$ & $0.069-5.31$ \\
Slope $\left(\mu \mathrm{A} \mathrm{M}{ }^{-1}\right)$ & $2.53 \times 10^{7}$ & $1.39 \times 10^{7}$ & $1.62 \times 10^{7}$ \\
SE of slope & $7.53 \times 10^{4}$ & $9.27 \times 10^{4}$ & $7.14 \times 10^{4}$ \\
Intercept $(\mu \mathrm{A})$ & -0.31 & 0.99 & 1.34 \\
SE of intercept & $5.10 \times 10^{-3}$ & $9.25 \times 10^{-3}$ & $7.48 \times 10^{-3}$ \\
Determination coefficient $\left(R^{2}\right)$ & 0.9991 & 0.9989 & 0.9983 \\
Number of measurements $(n)$ & 5 & $5.04 \times 10^{-9}$ & 5 \\
LOD $(\mathrm{M})$ & $3.79 \times 10^{-9}$ & 198.57 & $6.29 \times 10^{-9}$ \\
Sensitivity $\left(\mu \mathrm{A} \mu \mathrm{M}^{-1} \mathrm{~cm}^{-2}\right)$ & 361.43 & 2.18 for $3.12 \times 10^{-7}$ & 231.43 \\
Repeatability of peak current $(\mathrm{RSD} \%)$ & 1.32 for $3.2 \times 10^{-7}$ & 2.32 for $3.12 \times 10^{-7}$ & 1.46 for $3.23 \times 10^{-7}$ \\
Reproducibility of peak current $(\mathrm{RSD} \%)$ & 1.63 for $3.2 \times 10^{-7}$ & & 1.79 for $3.23 \times 10^{-7}$
\end{tabular}




\subsection{Applications of the $\mathrm{Sn}-\mathrm{CeO}_{2} \mathrm{NPs} / \mathrm{GCPE}$ in real sample} analysis

The analysis of DTIC in real samples is crucial for clinical applications using the proposed sensor probe. The practical applicability of the optimized sensor was successfully applied to the quantification of DTIC in a number of real samples such as human serum, human urine (Fig. S6 and S7†) and pharmaceutical vial (Fig. S8 $\dagger$ ). For this purpose, the real samples were prepared as described in the Experimental section (Section 2). To check the accuracy of the procedure, the samples were spiked with known and different amounts of DTIC. The aliquots of these prepared samples were analyzed in five times $(n=5)$ according to the recommended procedures. A linear dynamic range of $7.60 \times 10^{-8}$ to $6.59 \times 10^{-6} \mathrm{M}$ DTIC (for serum sample) and of $6.90 \times 10^{-8}$ to $5.31 \times 10^{-6} \mathrm{M}$ DTIC (for urine sample) were obtained and the analytical results are tabulated in Table 2 . The recoveries in serum and urine samples were found to lie in the range from $96.77 \%$ to $103.12 \%$ (Table $\mathrm{S} 2 \dagger$ ). The results obtained suggest that the proposed voltammetric sensor based on the $\mathrm{Sn}-\mathrm{CeO}_{2} \mathrm{NPs} / \mathrm{GCPE}$ is reliable and free from the matrix interferences in the analysis of human serum and urine samples.

The practical analytical utility of the $\mathrm{Sn}-\mathrm{CeO}_{2} \mathrm{NPs} / \mathrm{GCPE}$ was also illustrated by the determination of DTIC in pharmaceutical products (Fig. S8 $\dagger$ ). The standard addition method was applied in this analysis, and the results are listed in Table S3. $\uparrow$ The recovery of the spiked samples ranged between $98.00 \%$ and $100.40 \%$, indicating that the fabricated sensor could be efficiently used for the determination of DTIC in pharmaceutical samples.

\section{Conclusions}

In this work, $\mathrm{Sn}$ doped $\mathrm{CeO}_{2}$ nanoparticles were successfully synthesized and further employed to fabricate $\mathrm{Sn}-\mathrm{CeO}_{2} \mathrm{NPs} /$ GCPE for the first time. Characterization data of synthesized $\mathrm{Sn}-\mathrm{CeO}_{2} \mathrm{NPs}$ by XRD, EDX and TEM confirmed that the Sn replaces $\mathrm{Ce}$ site and that the crystal structure of $\mathrm{CeO}_{2}$ was retained as rutile phase up to the maximum loading of $5 \mathrm{wt} \%$ $\mathrm{Sn}$. The fabricated electrode was successfully used to study the electrochemical behavior of DTIC. The $\mathrm{Sn}-\mathrm{CeO}_{2} \mathrm{NPs} / \mathrm{GCPE}$ exhibited an excellent electrocatalytic activity towards the oxidation of DTIC. The $\mathrm{Sn}-\mathrm{CeO}_{2} \mathrm{NPs} / \mathrm{GCPE}$ offers a good, reliable and simple method for the selective determination of DTIC in phosphate buffer solution of $\mathrm{pH}$ 4.0. The $\mathrm{Sn}-\mathrm{CeO}_{2} \mathrm{NPs} / \mathrm{GCPE}$ not only shifted the oxidation potential of DTIC towards less positive potential but also enhanced its oxidation current when compared to undoped $\mathrm{CeO}_{2}$ modified and bare GC electrodes. The fabricated electrochemical sensor exhibits good selectivity, a wide linear range, lower detection limit, high sensitivity, storage stability and acceptable reproducibility. In addition, the $\mathrm{Sn}-\mathrm{CeO}_{2} \mathrm{NPs} / \mathrm{GCPE}$ was demonstrated to be useful for the detection of DTIC in pharmaceutical and human biological samples with good accuracy and precision. All these advantageous features make the proposed $\mathrm{Sn}-\mathrm{CeO}_{2} \mathrm{NPs} / \mathrm{GCPE}$ sensor successfully applied for the determination of DTIC in the clinical samples, which can be used to diagnose the health condition of patients.

\section{Live subject statement}

All experiments were performed in compliance with the relevant laws and Assiut University's guidelines. The analysis of DTIC in real samples such as human serum, human urine were approved by the ethics committees of Assiut Medical University - Joint Institutional Review Board. All of the subjects signed an informed consent form before examination.

\section{References}

1 M. M. Eggermont and J. M. Kirkwood, Re-evaluating the role of dacarbazine in metastatic melanoma: what have we learned in 30 years?, Eur. J. Cancer, 2004, 40, 1825-1836.

2 M. Spasova and E. Golovinski, Pharmacobiochemistry of arylalkyltriazenes and their application in cancer chemotherapy, Pharmacol. Ther., 1985, 27, 333-352.

3 X. Wang, Y. Li, S. Gong and D. Fu, A spectroscopic study on the DNA binding behavior of the anticancer drug dacarbazine, Spectrosc. Lett., 2002, 35, 751-756.

4 M. Sanada, M. Hidaka, Y. Takagi, T. Y. Takano, Y. Nakatsu, T. Tsuzuki and M. Sekiguchi, Modes of actions of two types of anti-neoplastic drugs, dacarbazine and ACNU, to induce apoptosis, Carcinogenesis, 2007, 28, 2657-2663.

5 D. T. King and J. T. Stewart, HPLC determination of dacarbazine, doxorubicin, and ondansetron mixture in 5\% dextrose injection on underivatized silica with an aqueousorganic mobile phase, J. Liq. Chromatogr., 1993, 16, 23092323.

6 D. Fiore, A. J. Jackson, M. S. Didolkar and V. R. Dandu, Simultaneous determination of dacarbazine, its photolytic degradation product, 2-azahypoxanthine, and the metabolite 5-aminoimidazole-4-carboxamide in plasma and urine by high-pressure liquid chromatography, Antimicrob. Agents Chemother., 1985, 27, 977-979.

7 A. Haque and J. T. Stewart, Isocratic determination of dacarbazine and related impurities 2-azahypoxanthine and 5-amino-imidazole-4-carboxamide by HPLC on an avidin protein column, J. Liq. Chromatogr. Relat. Technol., 1999, 22, 933-943.

8 Y. Liu, W. Zhang and Y. Yang, Validated hydrophilic interaction LC-MS/MS method for simultaneous quantification of dacarbazine and 5-amino-4-imidazolecarboxamide in human plasma, Talanta, 2008, 77, 412-421.

9 A. J. Ordieres, A. C. Garcia, P. T. Blanco and W. F. Smyth, An electroanalytical study of the anticancer drug dacarbazine, Anal. Chim. Acta, 1987, 202, 141-149.

10 M. Song, R. Zhang and X. Wang, Nano-titanium dioxide enhanced biosensing of the interaction of dacarbazine with DNA and DNA bases, Mater. Lett., 2006, 60, 2143-2147.

11 J. R. Barreira, A. Costa, A. J. Miranda and P. Tunon, Electrochemical oxidation of dacarbazine and its major metabolite (AIC) on carbon electrodes, Electroanalysis, 1989, 1, 529-534.

12 M. U. Ahmed, M. M. Hossain and E. Tamiya, Electrochemical biosensors for medical and food applications, Electroanalysis, 2008, 20, 616-626. 
13 Y. Xiao and C. M. Li, Nanocomposites: From fabrications to electrochemical bioapplications, Electroanalysis, 2008, 20, 648-662.

14 N. Golego, S. A. Studenikin and M. Cocivera, Sensor photoresponse of thin-film oxides of zinc and titanium to oxygen gas, J. Electrochem. Soc., 2000, 147, 1592-1594.

15 X. Wang, J. Song, J. Liu and Z. L. Wang, Direct-Current Nanogenerator Driven by Ultrasonic Waves, Science, 2007, 316, 102-105.

16 K. Keren, R. S. Berman, E. Buchstab, U. Sivan and E. Braun, DNA-templated carbon nanotube field-effect transistor, Science, 2003, 302, 1380-1382.

17 H. K. Maleh, S. Rostami, V.-K. Gupta and M. Fouladgar, Evaluation of $\mathrm{ZnO}$ nanoparticle ionic liquid composite as a voltammetric sensing of isoprenaline in the presence of aspirin for liquid phase determination, J. Mol. Liq., 2015, 201, 102-107.

18 M. Baghayeri, E.-N. Zare and M.-M. Lakouraj, A simple hydrogen peroxide biosensor based on a novel electromagnetic poly(p-phenylenediamine) and $\mathrm{Fe}_{3} \mathrm{O}_{4}$ nanocomposite, Biosens. Bioelectron., 2014, 55, 259-265.

$19 \mathrm{~S}$. Das and V. Jayaraman, $\mathrm{SnO}_{2}$ : A comprehensive review on structures and gas sensors, Prog. Mater. Sci., 2014, 66, 112255.

20 M. Ibrahim, Y. Temerk, H. Ibrahim and M. Kotb, Indium oxide nanoparticles modified carbon paste electrode for sensitive voltammetric determination of aromatase inhibitor formestane, Sens. Actuators, B, 2015, 209, 630-638.

21 N. Lavanya, S. Radhakrishnan and C. Sekar, Fabrication of hydrogen peroxide biosensor based on $\mathrm{Ni}$ doped $\mathrm{SnO}_{2}$ nanoparticles, Biosens. Bioelectron., 2012, 36, 41-47.

22 N. Lavanya, S. Radhakrishnan, C. Sekar, M. Navaneethan and Y. Hayakawa, Fabrication of $\mathrm{Cr}$ doped $\mathrm{SnO}_{2}$ nanoparticles based sensor for the selective determination of riboflavin in pharmaceuticals, Analyst, 2013, 138, 20612067.

23 N. Lavanya, S. Radhakrishnan, N. Sudhan, C. Sekar, S. Leonardi, C. Cannilla and G. Neri, Fabrication of folic acid sensor based on the $\mathrm{Cu}$ doped $\mathrm{SnO}_{2}$ nanoparticles modified glassy carbon electrode, Nanotechnology, 2014, 25, 295501.

24 S. D. Bukkitgar, N. P. Shetti, R. M. Kulkarni and M. R. Doddamani, Electro-oxidation of nimesulide at $5 \%$ barium-doped zinc oxide nanoparticle modified glassy carbon electrode, J. Electroanal. Chem., 2016, 762, 37-42.

25 N. Lavanya, C. Sekar, S. Ficarra, E. Tellone, A. Bonavita, S. G. Leonardi and G. Neri, A novel disposable electrochemical sensor for determination of carbamazepine based on $\mathrm{Fe}$ doped $\mathrm{SnO}_{2}$ nanoparticles modified screen-printed carbon electrode, Mater. Sci. Eng., C, 2016, 62, 53-60.
26 N. Lavanya, E. Fazio, F. Neri, A. Bonavita, S. G. Leonardi, G. Neri and C. Sekar, Electrochemical sensor for simultaneous determination of ascorbic acid, uric acid and folic acid based on $\mathrm{Mn}-\mathrm{SnO}_{2}$ nanoparticles modified glassy carbon electrode, J. Electroanal. Chem., 2016, 770, 23-32.

27 E. R. Brown and R. F. Large, in Physical Methods of Chemistry, ed. A. Weissberger and B. W. Rossiter, Wiley Inter science, Rochester New York, 1964, p. 423.

28 E. Aneggi, D. Wiater, C. de Leitenburg, J. Llorca and A. Trovarelli, Shape-dependent activity of ceria in soot combustion, ACS Catal., 2014, 4, 172-181.

29 J. Li, Z. Zhang, Z. Tian, X. Zhou, Z. Zheng, Y. Ma and Y. Qu, Low pressure induced porous nanorods of ceria with high reducibility and large oxygen storage capacity: synthesis and catalytic applications, J. Mater. Chem. A, 2014, 2, 16459-16466.

30 R. Rao, M. Yang, C. Li, H. Dong, S. Fanga and A. Zhang, A facile synthesis for hierarchical porous $\mathrm{CeO}_{2}$ nanobundles and their superior catalytic performance for $\mathrm{CO}$ oxidation, J. Mater. Chem. A, 2015, 3, 782-788.

31 A. B. Kehoe, D. O. Scanlon and G. W. Watson, Role of lattice distortions in the oxygen storage capacity of divalently doped $\mathrm{CeO}_{2}$, Chem. Mater., 2011, 23, 4464-4468.

32 Y. Temerk and H. Ibrahim, A new sensor based on In doped $\mathrm{CeO}_{2}$ nanoparticles modified glassy carbon paste electrode for sensitive determination of uric acid in biological fluids, Sens. Actuators, B, 2016, 224, 868-877.

$33 \mathrm{H}$. Ibrahim and Y. Temerk, A novel electrochemical sensor based on $\mathrm{B}$ doped $\mathrm{CeO}_{2}$ nanocubes modified glassy carbon microspheres paste electrode for individual and simultaneous determination of xanthine and hypoxanthine, Sens. Actuators, B, 2016, 232, 125-137.

$34 \mathrm{Y}$. Wu and $\mathrm{C}$. Lin, The microstructures and property analysis of aliovalent cations $\left(\mathrm{Sm}^{3+}, \mathrm{Mg}^{2+}, \mathrm{Ca}^{2+}, \mathrm{Sr}^{2+}, \mathrm{Ba}^{2+}\right)$ co-doped ceria-base electrolytes after an aging treatment, Int. J. Hydrogen Energy, 2014, 39, 7988-8001.

35 R. N. Goyal, V. K. Gupta and S. Chatterjee, Voltammetric biosensors for the determination of paracetamol at carbon nanotube modified pyrolytic graphite electrode, Sens. Actuators, B, 2010, 149, 252-258.

36 E. Laviron, General expression of the linear potential sweep voltammogram in the case of diffusionless electrochemical systems, J. Electroanal. Chem., 1979, 101, 19-28.

37 E. Laviron, The use of linear potential sweep voltammetry and of a.c. voltammetry for the study of the surface electrochemical reaction of strongly adsorbed systems and of redox modified electrodes, J. Electroanal. Chem., 1979, 100, 263-270.

38 J. Sangster, Log Kow Databank A, Databank of Evaluated Octanol-Water Partition Coefficients ( $\log$ P) on Microcomputer Diskette, Sangster Res Lab, 1993. 